\title{
The Effect of Affordable Care Act Medicaid Expansion on Post-Displacement Labor Supply among the Near-Elderly
}

Chichun Fang

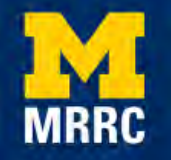

Project \#: UM117-17 


\title{
The Effect of Affordable Care Act Medicaid Expansion on Post-Displacement Labor Supply among the Near-Elderly
}

\author{
Chichun Fang \\ University of Michigan
}

September 2017

\author{
Michigan Retirement Research Center \\ University of Michigan \\ P.O. Box 1248 \\ Ann Arbor, MI 48104 \\ www.mrrc.isr.umich.edu
}

(734) 615-0422

\section{Acknowledgements}

The research reported herein was performed pursuant to a grant from the U.S. Social Security Administration (SSA) funded as part of the Retirement Research Consortium through the University of Michigan Retirement Research Center Award RRC08098401-09. The opinions and conclusions expressed are solely those of the author(s) and do not represent the opinions or policy of SSA or any agency of the federal government. Neither the United States government nor any agency thereof, nor any of their employees, makes any warranty, express or implied, or assumes any legal liability or responsibility for the accuracy, completeness, or usefulness of the contents of this report. Reference herein to any specific commercial product, process or service by trade name, trademark, manufacturer, or otherwise does not necessarily constitute or imply endorsement, recommendation or favoring by the United States government or any agency thereof.

\section{Regents of the University of Michigan}

Michael J. Behm, Grand Blanc; Mark J. Bernstein, Ann Arbor; Shauna Ryder Diggs, Grosse Pointe; Denise Ilitch, Bingham Farms; Andrea Fischer Newman, Ann Arbor; Andrew C. Richner, Grosse Pointe Park; Ron Weiser, Ann Arbor; Katherine E. White, Ann Arbor; Mark S. Schlissel, ex officio 


\title{
The Effect of Affordable Care Act Medicaid Expansion on Post-Displacement Labor Supply among the Near-Elderly
}

\begin{abstract}
Expanded health-insurance coverage under the Affordable Care Act (ACA) provides alternative channels to obtain health-insurance coverage outside employment, which in theory may affect whether people want to work, how much they work, and the sorting of individuals into jobs. Although health insurance exchanges are available in all states, ACA Medicaid expansion is only available in states that chose to expand Medicaid coverage. The state-level variation in timing of Medicaid expansion provides a quasi-experiment setting that can be used to examine how healthinsurance coverage affected labor supply. In this paper, I study how Medicaid expansion affects the labor supply and re-employment outcomes of displaced (involuntarily unemployed) workers who are near-elderly, low-income, nonmarried, childless, and nondisabled. Data from 2011-2016 waves of monthly Current Population Survey (CPS) as well as 2010-2016 waves of Displaced Workers Survey (DWS) are used. Results from a discrete-choice model using the CPS suggest that, some displaced workers in expansion states became less likely to exit unemployment to employment while some others became more likely to exit unemployment to not-in-labor-force immediately following Medicaid expansion. While robustness tests suggest this may partly be attributed to state-level idiosyncrasies, my results reject large and persistent effect of Medicaid expansion on unemployment exits. The DWS does not have enough statistical power to identify the difference in re-employment outcomes between displaced workers in expansion and nonexpansion states.
\end{abstract}

\section{Citation}

Fang, Chichun. 2017. “The Effect of Affordable Care Act Medicaid Expansion on PostDisplacement Labor Supply among the Near-Elderly.” Ann Arbor, MI: University of Michigan Retirement Research Center (MRRC) Working Paper, WP 2017-370.

http://mrrc.isr.umich.edu/wp370/ 


\section{Introduction}

The Affordable Care Act (ACA) health-insurance coverage expansion provides an alternative channel to obtain health insurance outside employment. Before the ACA, a majority of the U.S. nonelderly population obtained health-insurance coverage through employment. The link between employment and health-insurance coverage is likely weakened with the expanded coverage under the ACA, which may affect whether people want to work, how much they work, and the sorting of individuals into jobs. Theoretically, such expanded coverage should reduce the level of "job lock" (in which, to keep health-insurance coverage, a worker stays with a job that he/she would otherwise leave) and "job push" (in which, to gain health-insurance coverage, a worker takes a job that he/she would otherwise not take) (Gruber, 2000; Gruber and Madrian, 2004).

In this paper, I examine how the ACA Medicaid expansion affected unemployment exits and subsequent re-employment outcomes of near-elderly displaced (involuntarily unemployed) workers. Displaced workers by definition have no employers or jobs to be locked into; however, the reduction in "job push" suggests displaced workers are less likely to return to work, at least in the short run. With expanded health-insurance coverage outside employment, displaced workers may be able to afford to spend more time in job search in order to find better job match (rather than accepting the first offer that sponsors health insurance); they may also choose to stop job search and quit the labor force altogether. In other words, expanded health-insurance coverage affects displaced workers through a similar mechanism as extended unemployment insurance (UI) benefits do: they both have the potential to reduce unemployment exit to employment or increase unemployment exit to "not-in-labor-force” (NILF). 
Whether and how ACA health-insurance coverage expansion affects unemployment exits among the displaced workers have important implications on economic well-being in the long run. In particular, if the ACA-expanded coverage extends job search and improves the job quality/match upon re-employment, it will have a positive effect on displaced workers beyond health-insurance coverage itself. This is especially critical for displaced workers who are approaching retirement age, i.e. the near-elderly. Displaced workers approaching retirement age are less likely on average to be employed again. Among those who are eventually re-employed, displaced workers of this age group have longer unemployment spells, are more likely to find part-time jobs, and have lower earnings upon re-employment compared to younger displaced workers (Chan and Stevens, 1999; 2001; Couch and Placzek, 2010; Farber, 2017). Displaced workers with longer job tenure, who tend to be older and have higher levels of firm-specific human capital, also suffer from larger earnings loss upon re-employment (Jacobson, LaLonde, and Sullivan, 1993; Hallock 2009).

In a broader context, ACA health-insurance coverage expansion can also improve retirement security if it helps near-elderly displaced workers to land better jobs through a longer job search. During the Great Recession and its aftermath, many defined-contribution retirement account holders lost significant amounts in their retirement wealth. Displaced workers approaching retirement age were extremely vulnerable, as they lost the opportunities to continue building their retirement wealth and might even have to draw benefits before the account balance bounced back as the economy recovered. Consequently, it is crucial for these workers to be able to not only return to work, but also find good job matches: A better post-displacement job benefits displaced workers through both higher earnings as well as opportunities to "catch up" in retirement savings. 
The ACA-health-insurance coverage expansion is made of two parts: subsidized plans through health insurance exchanges (available in all states) and expanded Medicaid (only available in states that chose to expand Medicaid coverage). The state-level variation in whether and when Medicaid coverage was expanded provides a quasi-experiment setting that allows researchers to identify the effect of the ACA Medicaid expansion on labor market outcomes. I study how Medicaid expansion affected post-displacement labor supply (unemployment exits and re-employment) and re-employment outcomes of near-elderly (age 51-61) displaced workers who are low-income (annual household income less than \$15,000), nonmarried, childless, and nondisabled. This subpopulation likely could only obtain health-insurance coverage through employment before the ACA, and hence should benefit the most from Medicaid expansion in states that chose to expand Medicaid. Additionally, to the extent that the magnitudes of reduction in job push may depend on demand for health insurance, the effects of Medicaid expansion on labor sully and subsequent re-employment outcomes should be the most prominent among the near-elderly who are not yet age-eligible for Medicare.

I estimate both discrete choice and difference-in-differences models using data from the basic monthly Current Population Survey (CPS) and its biennial Displaced Workers Survey (DWS) supplement. Results from the basic monthly CPS suggest that Medicaid expansion moderately affected unemployment exits in the short run — as a group, displaced workers in expansion states were less likely to quit unemployment to employment and more likely to quit unemployment to not-in-labor force than displaced workers in nonexpansion states around the time when Medicaid was expanded. Nevertheless, robustness tests reject large and persistent effects of Medicaid expansion on unemployment exits. Results using the DWS do not have 
enough statistical power to identify the difference in labor supply and re-employment outcomes in the long run.

The rest of the paper is organized thus: Economic theories that motivate this research are introduced in Section II, data and identification strategies are detailed in Section III, and results are presented in Sections IV. Section V discusses the results and concludes the paper.

\section{ACA Medicaid Expansion and Post-Displacement Labor Supply}

A. Expanded Coverage, Unemployment Exits, and Subsequent Re-employment Outcomes

Most of the non-elderly population in the U.S. obtains health-insurance coverage through employment. For many people, having a household member working for an employer who sponsors health insurance benefits is the only way to obtain coverage due to the prohibitive premium cost of non-group health insurance policies on the market. Such institutional arrangement leads to both “job lock” and “job push,” where individuals stay in or take up jobs that they would otherwise not in order to obtain health-insurance coverage. Previous research has shown that when there are alternative sources of health-insurance coverage outside employment, the degree of job push/lock can be reduced (Gruber, 2000; Gruber and Madrian, 2004).

The ACA facilitates alternative sources of health-insurance coverage outside employment through either state-level health insurance exchanges or expanded Medicaid. Among displaced workers, economic theories suggest that ACA-expanded health-insurance coverage will reduce job push. That is, with expanded coverage under the ACA, some displaced workers who would have taken up job offers as soon as possible in order to obtain health-insurance coverage might change their job search behaviors and hence labor supply. They may instead spend more time on the job search hoping to find a better job match or not work at all. Hence, expanded healthinsurance coverage can reduce labor supply among displaced workers, at least in the short run. 
Whether and how expanded health-insurance coverage reduce labor supply has important implications for public policy and individual well-being. Unemployment rates can increase in the short run if displaced workers spend more time in a job search in order to find a better job match; however, a better job match eventually benefits both the worker and the economy. On the other hand, unemployment rates can decrease if displaced workers choose to stop their job search and quit from the labor force, but this leads to negative consequences on workers' economic wellbeing in the long run. From the labor statistics perspective, the former reduces unemployment exits (to employment) while the latter increases unemployment exits to "not-in-labor-force" (NILF).

Furthermore, expanded health-insurance coverage affects unemployment exits in a very similar mechanism as extended unemployment insurance (UI) benefits do. Both health-insurance coverage expansion and extended UI benefits buffer financial shocks during the unemployment spell for displaced workers, and both create disincentives to work in the short run. Recent studies have shown that extended UI benefits during the Great Recession reduced the rate of unemployment exits to employment, but did not significantly increase unemployment exits to NILF (Rothstein, 2011; Farber, Rothstein, and Valletta, 2015; Farber and Valletta, 2015), and more generous UI benefits (in terms of either duration or amount) have also been shown to increase time spent in job search (Katz and Meyer, 1990; Meyer, 1990; Card and Levine, 2000; Lalive, 2008; Rothstein, 2011). Whether longer job search leads to better re-employment outcomes is theoretically ambiguous. On the one hand, a longer job search may lead to better job match and higher wages upon re-employment (Ehrenberg and Oaxaca, 1976; Acemoglu and Shimer, 2000; Centeno, 2004). On the other hand, a longer unemployment spell reduces re- 
employment wages as workers lose their skills (Addison and Portugal, 1989; Schmieder, Wachter, and Bender, 2016; Carrington and Fallick, 2017).

A major difference between expanded health-insurance coverage and extended UI benefits is how their values are perceived across different age groups. While each dollar of UI benefits has the same value across age groups, the "value" of health-insurance coverage likely differs by age. Older people on average have higher demand for health-insurance coverage. As Card, Dobkin, and Maestas (2008) show, demand for health care services increases monotonically with age, and demand for non-Medicare services increases with age until age 65 when Medicare “substitutes” non-Medicare health care services. Consequently, displaced workers of older ages (but not yet eligible for Medicare) should value the expanded healthinsurance coverage more and have stronger labor supply responses than their younger peers.

Assuming that expanded health-insurance coverage affects unemployment exits and labor supply of displaced workers in the same way as extended UI benefits do, we should expect lower unemployment exits and longer job search durations in the short run, as well as better reemployment outcomes in the long run, after the onset of ACA. The effect should be the most prominent among the near-elderly displaced workers, who value health-insurance coverage the most.

\section{B. Medicaid Expansion under the Affordable Care Act}

Expanded coverage under the ACA has two components: health insurance exchanges and Medicaid expansion. The original design under the ACA was to provide subsidized coverage through health insurance exchanges for people whose household income was greater than 138 percent of the federal poverty level (FPL), and relied on state-level Medicaid expansion to cover those below 138 percent of the FPL. Nevertheless, in National Federation of Independent Business v. Sebelius, the U.S. Supreme Court made it optional for individual states to expand 
Medicaid coverage. As a result, a total of 24 states decided not to expand health-insurance coverage when major provisions of the ACA went into effect, and 19 of them still did not expand Medicaid coverage as of the end of 2016 (Miller and Wherry, 2017). Although health insurance exchanges are available in all states and provide largely similar level of coverage, only those who reside in a state that expanded its Medicaid can benefit from the Medicaid expansion component of the ACA. The variation in timing of Medicaid expansion at the state level can be used as a quasi-experiment setting to study the effect of the ACA Medicaid expansion on labor market outcomes.

Depending on whether and when a state expanded its Medicaid coverage, I follow the categorization used in Levy, Buchmueller, and Nikpay (2016) and split U.S. states into four categories: early expansion (those that expanded before January 2014), expansion (expanded in January 2014), late expansion (expanded between January 2014 and December 2016), and noexpansion (had not yet expanded as of January 2017). I also used additional information (Sommers et al., 2013; Sommers, Kenney, and Epstein 2014) to determine the exact timing and generosity of early expansion. A map of U.S. states color-coded in these four categories is shown in Figure I.

\section{Previous Research on ACA Medicaid Expansion and Labor Supply}

While the ACA Medicaid expansion has been shown to increase health-insurance coverage in expansion states (Courtemanche et al., 2017; Duggan, Goda, and Jackson, 2017; Kaestner et al., 2017; Miller and Wherry, 2017), studies have not yet found any negative relationship between ACA Medicaid expansion and labor supply despite the clear predictions in economic theories. Levy, Buchmueller, and Nikpay (2016) finds no difference in the stock of workers across employment status (employed, unemployed, retired, etc.) in expansion states relative to states that did not expand Medicaid using the basic monthly Current Population 
Survey. Gooptu et al. (2016) finds no difference in the flow across employment status in expansion versus nonexpansion states by utilizing the two-year panel structure of the CPS. Along the intensive margin, the evidence that Medicaid expansion leads to more part-time workers is also quite limited (Gooptu et al., 2016; Moriya, Seldon, and Simon, 2016). Leung and Mas (forthcoming) estimates the aggregate employment at the state level and also finds no relationship between ACA Medicaid expansion and employment. If anything, Medicaid expansion might have slightly increased labor supply among those who likely would have benefited (Duggan, Goda, and Jackson, 2017; Kaestner et al., 2017), although the effect is not large.

One of the possible explanations to such mixed results is that expanded health-insurance coverage has heterogeneous effects on both extensive and intensive margins across different, narrowly-defined groups, and the population average effect across these groups may have canceled out each other. For example, although economic theories predict reduced labor supply following the reductions in job lock and job push after the onset of ACA expanded coverage, it is not inconceivable that some people who intentionally kept income low enough in order to qualify for Medicaid before the ACA (i.e., the "Medicaid notch," where a worker whose earnings might otherwise be higher chooses to work less in order to remain Medicaid eligible) would instead increase labor supply now that they can obtain health-insurance coverage under expanded Medicaid or through health insurance exchanges (Hamersma, 2013). Hence, focusing on a more narrowly-defined subpopulation would help to address the concern of heterogeneous effects across the overall population.

\section{D. $\quad$ Sample Restriction and Research Questions}

In this paper, I focus on the post-displacement labor supply and re-employment outcomes among displaced workers who are near-elderly (age 51-61), low-income (household income less 
than $\$ 15,000$ ), nonmarried, childless, and nondisabled. Among displaced workers, the first order change in labor supply has to be along the extensive margins (in the form of unemployment exits), which can be captured by changes in employment status. Given that my identification strategy relies on the state-level variation in Medicaid expansion, I restrict my sample to those who would most likely benefit from Medicaid expansion: This subpopulation was unlikely to be eligible for any public health-insurance coverage before the ACA and could only obtain affordable health-insurance coverage through employment if there were no expanded coverage. Finally, I restrict the sample to those between ages 51 and 61. As previously discussed, nearelderly workers should respond the most to expanded health-insurance coverage due to their higher demand for health care services. Those aged between 62 and 64 are excluded from my sample to isolate the possible confounding relationship between labor supply and eligibility for Social Security early retirement benefit starting at age 62 .

Displaced workers by definition were separated from their jobs involuntarily. The distinction between voluntary and involuntary unemployment is important: Involuntary job displacement is generally considered as an exogenous shock beyond the worker's control. On the other hand, a decision to quit job voluntarily can be endogenous and reflects individual heterogeneity or information not observable to econometricians, such as availability of other health insurance plans, as well as demand for health-insurance coverage or health care services in general. Hence, those who quit jobs voluntarily are not included in my study to avoid the possible endogeneity between demand for health insurance and employment among these workers.

I examine both short-term and long-term effects of ACA Medicaid expansion on labor supply and post-displacement job outcomes. In terms of short-term outcomes, I assess whether 
Medicaid expansion affects unemployment exits among near-elderly displaced workers. Immediately following the month after a state expands Medicaid, expansion, in theory, acts like UI benefits and can affect the likelihood of unemployment exits. Medicaid may decrease unemployment exit to employment and extend job search, and it may also increase unemployment exit to NILF. These two effects operate in opposite directions, and it is theoretically ambiguous which one of the two dominates. Although the study of extended UI benefits during the Great Recession suggests that more generous UI benefits led to longer job search but did not increase unemployment exit to NILF among displaced workers, Rutledge (2016) showed that additional financial resources given to old-age displaced workers tend to increase retirement (that is, unemployment exit to NILF) rather than extending job search.

In terms of longer-term outcomes, I assess whether near-elderly displaced workers who reside in states that expanded Medicaid are more likely to become re-employed and whether they also see better re-employment job outcomes. Extended job search has the potential to lead to better job match and hence re-employment outcomes, which are crucial to near-elderly displaced workers, as they suffer larger earning loss due to displacement than younger displaced workers (Chan and Stevens, 1999 and 2001; Couch and Placzek, 2010; Farber, 2017). Re-employment job outcomes also have important implications on the well-being of near-elderly displaced workers in the aftermath of the Great Recession. With the recent shift from defined benefit to defined contribution retirement plans, workers lose both jobs and opportunities to keep accumulating their retirement wealth upon displacement. Better re-employment outcomes afford them opportunities to catch up on retirement savings. In such a context, the ACA not only improves the lives of near-elderly displaced workers in the short run through the availability of 
affordable health-insurance coverage, but also has the potential to improve long-term economic outcomes, including retirement preparedness.

\section{Data and Econometric Models}

I use two sets of data from the Current Population Survey (CPS). The basic monthly CPS between January 2011 and December 2016 are used to study how ACA Medicaid expansion affected unemployment around the time when Medicaid was expanded, and 2010, 2012, 2014, and 2016 waves of the Displaced Worker Survey (DWS) are used to examine the longer-term outcomes of post-displacement labor supply upon Medicaid expansion.

\section{A. Basic Monthly CPS}

The basic monthly CPS between January 2011 and December 2016 are used to study how the ACA Medicaid expansion affected the likelihood of unemployment exits. Unemployment exits are identified by using the "panel" structure of the CPS. Upon being selected into the CPS, a household stays in the sample for four months, goes out for eight months, and then re-enters the sample for another four months. It is therefore possible to link CPS respondents across months when they are in the sample and construct an unbalanced monthly panel in which each respondent has two four-month spells. Within each four-month spell, it can be observed whether a CPS respondent who is unemployed in a given month remains unemployed, becomes employed, or quits the labor force in the following month.

Although the CPS sampling unit is at the household level, each member in the household is interviewed by the CPS. Within each year/month, CPS respondents can be uniquely identified by the variables HRHHID, HRHHID2, and PERNUM. Theoretically, these variables remain constant for a CPS respondent while he/she is interviewed by the CPS. However, due to attrition 
from the survey, household split, or recording errors, linking respondents across waves can be complicated (Madrian and Lefgren, 2000). Some respondents drop out from one month to another, and some respondents never return for the second Four-month period after staying through the first four-month period. During the sample period used in this paper, roughly 10 percent of respondents do not have corresponding observations in adjacent months in the same four-month period. These respondents are dropped from my analysis. The "attrition" in this paper is lower than in the papers that utilize the CPS as a two-year panel. In those papers, a CPS respondent has to be present in both of the four-month periods, resulting in an attrition of about 30 percent. In contrast, a CPS respondent who stays in sample for the first four months but never returns would still remain in my study if this respondent satisfies the inclusion criteria based on employment status, age, marital status, number of kids, and income.

Only CPS respondents who are involuntarily unemployed at any time during the fourmonth spell are included in my analysis. Respondents who are voluntarily unemployed are not included to avoid potential endogeneity between the demand for health insurance and employment among these workers. Given that an individual is involuntarily unemployed ("atrisk”) in a given month, three possible employment outcomes can occur in the following month: becoming employed, quitting the labor force, or remaining unemployed. The first two outcomes are considered as “unemployment exits.” During a four-month period, an “at-risk” individual has at most three “opportunities” to exit unemployment. (Since the labor market outcome in month five is not available, I cannot observe whether an "at-risk” individual exits in the end of month four.) Upon exiting unemployment, the remaining observations of that individual-spell are dropped from the sample. If a displaced worker is never re-employed during the four-month period, this individual's unemployment spell is "right-censored" and all the observations remain 
in the sample. That is, an unemployed worker remains in my data until unemployment exit or right-censoring.

The employment status reported in the CPS may also contain measurement error. For the purpose of this paper, the biggest concern over the measurement error is the transition into or out of unemployment due to misreports in employment status. For example, for a respondent who was employed for all the four months in the panel but misreported the employment status as "unemployed" in month three, the data would suggest transitions from employment to unemployment in month three and from unemployment to employment in month four. Similarly, for a respondent who was always unemployed but misreported as employed in month three, the data would show a transition out of unemployment in month 3 and then back to unemployment in month four. Measurement errors in employment status hence lead to false-positive unemployment exits. To account for such potential problems, I recode "unemployed” as "employed" if an "unemployed" month is sandwiched between two "employed" months. I also recode "employed" as "unemployed" if an "employed" month is sandwiched between two "unemployed” months. That is, a sequence of E-U-E (where E stands for “employed” and U stands for "unemployed”) was recoded as E-E-E and U-E-U recoded as U-U-U. Such recoding strategy is consistent with the recent literature on the relationship between unemployment benefit generosity and unemployment exits (Farber, Rothstein, and Valletta, 2015). Note that, by construction, such recoding also drops all "true" unemployment spells that only lasted one month.

As previously mentioned, the sample is further restricted to adults who are not disabled, not married, childless, between ages 51 and 61 at the time of survey, and whose annual household income is less than $\$ 15,000$, roughly 138 percent of the FPL for a single household. 
Unlike other work that examines the effect of ACA on labor supply, my CPS sample includes individuals from all U.S. states, rather than just individuals from states that either expanded Medicaid in January 2014 or never expanded, since this part of the analysis relies on an identification assumption more flexible than what is required in a difference-in-differences design. Descriptive statistics of selected variables in my CPS sample are shown in Table I. The last few rows in Table I show the average likelihood of unemployment exits in the sample: overall, slightly more than 20 percent of displaced workers exit unemployment in each month; about 9 percent (on average) of them exit to employment, and about 14 percent exit to not-inlabor-force.

In any given month, a displaced worker can choose whether to stay unemployed, take a job, or quit the labor force. I estimate a logistic discrete choice model similar to the one in Farber, Rothstein, and Valletta (2015):

$$
y_{i s t}^{*}=X_{i s t} \beta+Z_{s t} \lambda+A C A_{s t} \alpha+U I_{i s t} \gamma+\omega_{s}+\psi_{t}+\varepsilon_{i s t}
$$

an individual $i$ in state $s$ would exit unemployment in year-month $t$ if the latent variable $y_{i s t}^{*}$ is positive. Hence, equation [1] assesses the flow rather than the stock of labor market outcome. $A C A_{s t}$ is a binary variable and takes value of 1 if state $s$ in year-month $t$ has expanded Medicaid. For example, Michigan expanded Medicaid in April 2014, so this $A C A_{s t}$ indicator for Michigan was 0 between January 2008 and March 2014 and 1 from April 2014 beyond. The coefficient $\alpha$ captures the effect of ACA Medicaid expansion on the likelihood of unemployment exits, which can be interpreted as the "expansion-induced changes" in unemployment exits. This equation only identifies a very short-term effect: how the ACA Medicaid expansion affected unemployment exits immediately following the month when Medicaid was expanded. 
$X_{i s t}$ is a standard set of control variables that includes gender, race, age, highest level of education (less then high school, high school, some college, and college or more), categories of family income, and duration of unemployment through year-month $t . Z_{s t}$ is state-level labor market condition in year-month $t$ and includes the number of unemployed workers filing the initial claim for unemployment benefit (in logarithm), number of unemployed workers receiving unemployment benefits (in logarithm), number of workers covered by unemployment insurance (in logarithm), and state unemployment rate. These data are obtained from the Department of Labor website (accessed on March 23, 2017).

$U I_{i s t}$ is a binary variable that takes value of 1 if, as of time $t$, the unemployment duration of an individual $i$ in state $s$ is shorter than the maximum availability of unemployment benefit (and therefore is still receiving benefits if the individual $i$ is eligible for unemployment benefit). ${ }^{1}$ $U I_{i s t}$ is a state-month level measure that captures the variation in UI benefits generosity. Following the Great Recession, the availability of unemployment benefits had been substantially expanded, from the regular 26 weeks to 99 weeks in many states. Such extensions were phased out starting from 2013. Nevertheless, the extension and phase-out of unemployment benefits were enacted at the state level, resulting in a certain degree of variation across states. Figure II plots the median of "maximum unemployment benefits availability" in expansion versus nonexpansion states, and it suggests nonexpansion states on average had less generous unemployment benefits between 2010 and 2013. $U I_{i s t}$ is included in the model to capture the confounding effect of changing UI benefits generosity on unemployment exits.

Finally, $\omega_{s}$ and $\psi_{t}$ are, respectively, full sets of state and time (year-month) dummy variables. The model hence controlled for the state-year/month variations in factors that affected

\footnotetext{
${ }^{1}$ I relied on the online appendix of Farber, Rothstein, and Valletta (2015) for state-month level of maximum UI benefits through June 2014. I collected such data between July 2014 and December 2016 on my own.
} 
labor supply, as well as idiosyncratic state/time variations that might have affected the unemployment exits.

\section{B. $\quad$ Displaced Workers Survey}

The DWS is administered every other year in January since 1984, and covers respondents who had been displaced for reasons not related to the worker's own performance. The big three reasons of displacement in the DWS are "plant closing," "insufficient work," and "position abolished.” By construction, DWS only includes those who lost their jobs involuntarily. For these displaced workers, the DWS asks detailed information regarding the job characteristics in the job lost and when the job was lost. If the displaced worker was subsequently re-employed, the DWS also asks about the duration of job search as well as the characteristics of the reemployment job. Four waves of the DWS — 2010, 2012, 2014, and 2016 — are used in this paper.

Each wave of the DWS used covers displaced workers who lost their jobs involuntarily within the three years prior to the survey. The inclusion/exclusion criteria of my DWS sample is somewhat different from my basic monthly CPS sample. I drop DWS respondents whose job displacements occurred more than two years prior to the survey, so my 2016 DWS sample covers workers who were displaced in 2014 and 2015, my 2014 DWS sample covers those displaced in 2012 and 2013, etc. I also drop DWS respondents residing in states that expanded Medicaid before December 2013 or after January 2014. (In my CPS sample, respondents from all 50 states were retained.) Hence, my 2016 DWS sample covers displaced workers who reside in states that either expanded Medicaid exactly in January 2014 or did not expand Medicaid at all. No displaced workers in my 2010, 2012, and 2014 DWS sample reside in states that had Medicaid expansion between 2008 and 2013, the years covered by these waves of DWS. This sample serves as a baseline control group. In other words, my identification strategy using the DWS 
sample is essentially a difference-in-differences design: No respondents in 2010-2014 DWS are subject to Medicaid expansion, while displaced workers in my 2016 DWS sample who live in states that expanded Medicaid in 2014 could benefit from Medicaid expansion. Descriptive statistics of my DWS sample are shown in Table II. Note that, in both expansion and nonexpansion states and both before and after the ACA, mean and median re-employment wages were lower than the wages in the pre-displacement jobs.

I estimate the following equation:

$$
Y_{i s t}=X_{i s t} \beta+\operatorname{Exp}_{s} \lambda+A C A_{t} \gamma+\left(\operatorname{Exp}_{s} \times A C A_{t}\right) \alpha+\omega_{s}+\psi_{t}+\varepsilon_{i s t}
$$

$Y_{i s t}$ is the outcome of interest. $\operatorname{Exp}_{s}$ is a binary variable equal to 1 if state $s$ is an expansion state. $A C A_{t}$ is a binary variable equal to 1 if the observation is from the 2016 DWS and, therefore, was displaced after the onset of ACA when expansion states expanded Medicaid coverage. $\operatorname{Exp}_{s} \times$ $A C A_{t}$ is an interaction term, and $\alpha$ can be interpreted as the difference-in-differences estimate that captures the effect of ACA Medicaid expansion on $Y_{i s t}$. Additionally, $X_{\text {ist }}$ is a set of control variables that includes gender, race, highest level of education (less then high school, high school, some college, and college or more), wage in the lost job, tenure in the lost job, and a dummy variable indicating whether a respondent lost the job more than one calendar year prior to the survey (versus within one calendar year prior to the survey). Finally, $\omega_{s}$ and $\psi_{t}$ are, respectively, census region and survey wave dummy variables.

I use DWS to examine longer-term outcomes, including the likelihood of employment as well as re-employment wages conditional on re-employment. Although the duration of job search is also an interesting outcome, DWS is not an ideal data source to examine the effect of ACA Medicaid expansion on job search durations. This is namely because the DWS only has job search duration for respondents who were re-employed at the time of survey. For displaced 
workers who were not yet re-employed at the time of survey, there is no information that can be used to calculate job search durations. (DWS only asks the year of displacement, not the month.) Consequently, for those who were not yet re-employed at the time of survey and have their unemployment spells "censored", there is no reliable measure on the duration of the unemployment spell.

\section{IV.Results}

\section{A. ACA Medicaid Expansion and Unemployment Exits}

Estimates from the logit discrete choice model are shown in Table III. Three models are estimated: overall unemployment exits (regardless whether it is exit to employment or exit to NILF), unemployment exit to employment, and unemployment exit to NILF. The only difference across these three models is how the lefthand-side variable is defined, and Table III reports the estimates of coefficient $\alpha$ in equation [1]. The numbers reported are already marginal effects from the logistic models. As previously explained, these numbers can be interpreted as the “expansion-induced changes" in unemployment exits.

ACA Medicaid expansion did not seem to have an effect on the overall unemployment exit rate. The coefficient in the first column is not statistically significant. After the overall unemployment exits are split into exit to employment and exit to NILF, however, ACA Medicaid expansion decreased unemployment exit to employment by 8.4 percentage points and increased unemployment exit to NILF by 8.6 percentage points in the month immediate following a state's expansion of Medicaid coverage. The numbers in the second and third columns are similar in their absolute values, meaning that opposite effect on unemployment exits essentially cancelled 
out each other. ${ }^{2}$ This also explains why ACA Medicaid expansion had no effect on overall unemployment exits in the first column. Recall from Table I that, on average, about 9 percent of displaced workers exit to employment and 14 percent exit to NILF in each month. Effects reported in Table III are hence quite sizable—virtually offsetting all exits to employment and increasing exit to NILF by 60 percent immediately following the onset of Medicaid expansion.

By its nature, the effect identified in a discrete choice model is the immediate response to Medicaid expansion. Just like results reported in the UI benefits literature that assess how change in UI generosity affected unemployment exits when UI availability was expanded or cut back, the numbers in Table III capture the immediate effect of unemployment exits following Medicaid expansion rather than the long-term response. However, while in theory UI benefits and Medicaid expansion should affect unemployment exits in similar ways, the timing of their effects can differ. A change in UI benefits generosity immediately affects whether a displaced worker "at the margin” (who is exhausting the benefits) receives the next benefit check; a change in Medicaid coverage arguably takes longer to take effect. Miller and Wherry (2017) show that eligible people may not always sign up for Medicaid immediately following the expansion; additionally, Medicaid capacity in some states seemed not to be able to meet the increased demand, causing delays in the delivery of health care services. This leads to two questions: whether the effect of Medicaid expansion on unemployment exits was fully revealed immediately following Medicaid expansion, and whether the effect can persist as displaced workers learned about the potential limitations of expanded Medicaid.

\footnotetext{
${ }^{2}$ The numbers reported in Table III were estimated in separated models. In results not reported here, I used an alternative strategy and estimated exits to employment and NILF together with a multinomial logit models. The marginal effect of ACA Medicaid expansion on exits to employment and NILF were -0.074 and 0.076, respectively, in the multinomial logit model. These estimates are qualitatively the same as those reported in Table III.
} 
These questions can be answered by "shifting” the onset of ACA Medicaid expansion around the actual year/month of implementation and re-estimating equation [1] to obtain the “expansion-induced changes” in unemployment exits in each of the alternate months. Results are shown in the top panel of Figure III. The vertical line at time $=0$ in the top panel of Figure III is the same as the estimates in Table III. The trends show the "expansion-induced changes" in unemployment exits up to 12 months before/after the actual implementation of ACA Medicaid expansion. While the "expansion-induced changes” in unemployment exit to NILF ticked up between zero and six months after Medicaid expansion, the exit to employment was lower not only between zero and six months after Medicaid expansion but also back to 12 months before Medicaid expansion. The numbers are only marginally significant, however.

One explanation to the effect of Medicaid expansion on unemployment before the onset of expansion observed in the top panel in Figure III can be attributed to the definition of "time zero" and how the control groups are defined. The top panel in Figure III basically "normalizes” the onset of ACA Medication across states to "time zero.” Although this makes sense in a model that assesses the effect at "time zero", it becomes problematic when the reference point is shifted. For example, Michigan expanded Medicaid three months after most of the expansion states expanded their Medicaid programs. Therefore, three months before Michigan’s “time zero” is not a time when there is no Medicaid expansion; instead, the labor market situation three months before Michigan’s Medicaid expansion picks up a lot of responses to Medicaid expansion in other states. To address this issue, the bottom panel in Figure III replicates the first panel, but only uses states that expanded Medicaid in January 2014 or did not expand Medicaid at all. That is, early- and late-expansion states are dropped. The estimates become much noisier due to smaller sample size and the lack in variation of when Medicaid was expanded. At no point in 
either trend is the "expansion-induced changes" in unemployment exit different from zero; nevertheless, the pattern suggests that unemployment exits moved in the same way as economic theories would have suggested (exit to employment decreased and exit to NILF increased) within six to eight months after Medicaid expansion. The bottom panel in Figure III also rules out large and persistent effect beyond month eight.

To summarize, results from my CPS sample suggest sizable effects on unemployment exits to employment and to NILF from ACA Medicaid expansion. The results nevertheless reject the hypotheses that the ACA Medicaid expansion had a long-term impact on unemployment exits among displaced workers.

\section{B. Job Search Duration and Re-employment Outcomes}

Table IV shows six sets of results from equation [2] based on various outcome variables and estimation methods. Again, results in Table IV come from six separate models, and each point estimate in Table IV is an estimate of coefficient $\alpha$ in equation [2] under various specifications. Panel A includes my entire DWS sample, and Panel B only includes those who were eventually re-employed.

In Panel A, near-elderly, low-income, nonmarried, childless, and nondisabled displaced workers who live in states that expanded Medicaid in January 2014 are not different from those who live in nonexpansion states in the likelihood of quitting labor force or becoming reemployed. In Panel B, displaced workers in expansion states who were re-employed on average spent less time in job search relative to those in nonexpansion states, but there is no difference in re-employment wages. It is hard to explain why displaced workers in expansion states spent less time in the job search — economic theories imply that, if anything, displaced workers in expansion states should spend a longer time in their job search, not shorter. A closer examination of the data suggests that this result is partly driven by a few displaced workers in nonexpansion 
states who spent more than 90 weeks before becoming re-employed. This being said, the duration of job search between expansion and nonexpansion states warrants more research.

As previously mentioned, estimating duration models using the DWS requires some caution. The last columns in Panels A and B nevertheless show the estimates from Cox proportional hazard models. The data structure needed in duration models is different from what is used in other estimates in Table IV. To estimate a duration model, I duplicate the record of each DWS respondent by $N$ times, where $N$ is the number of weeks spent in job search (for those eventually re-employed) or the number of weeks since job displacement (for those who were not employed at the time of survey). The week of displacement is labeled as week 1, and DWS respondents remain unemployed until week $N$ (if re-employed) or become right-censored (if not re-employed at time of survey). Since DWS contains no information on the timing of displacement, those who were displaced in the calendar year prior to the survey and were not reemployed at the survey are considered as having been displaced for 50 weeks. Similarly, those displaced between one and two years prior to the survey and not re-employed are considered as being displaced for 100 weeks. Table IV's last column in Panel A shows the coefficient on the interaction when the proportional hazard model is estimated with my entire DWS sample, and the last column in Panel B shows the estimation using those who were re-employed only. This coefficient on the interaction term indicates whether displaced workers in expansion states exit unemployment and became employed faster than those in nonexpansion states. Neither coefficient is statistically significant, suggesting no such difference in unemployment exits.

One potential concern about my DWS results is the small sample size due to the sample inclusion criteria. In Table V, I relax my sample inclusion rules a bit: Rather than using those 51 to 61 years old, I include those age 51 to 64 ; rather than restricting household income at $\$ 15,000$ 
or less, I double the threshold to $\$ 30,000$ or less (roughly 2.5 times federal poverty level for a single household). Other restrictions remain unchanged. Nevertheless, numbers in Table V do not qualitatively differ from those in Table IV. Except that displaced workers in expansion states spent less time in job search before becoming re-employed, there is no difference in reemployment outcomes across displaced workers in expansion versus nonexpansion states after the onset of the ACA Medicaid expansion.

\section{Conclusion}

In this paper, I study the effect of ACA Medicaid expansion on the labor supply and subsequent re-employment outcomes among a subpopulation of the labor force - those who are involuntarily unemployed. I further restrict the sample to those who are the most likely to benefit from Medicaid expansion: near-elderly, low-income, nonmarried, childless, and nondisabled. I find evidence that, in states that expanded Medicaid, some unemployed workers were less likely to become re-employed and some were more likely to quit the labor force within six to eight months following Medicaid expansion. However, my results do reject large and persistent effect of ACA Medicaid expansion on the labor supply among displaced workers. I also assess whether the effect of Medicaid expansion translated to differences in long-term re-employment outcomes between displaced workers who live in states that expanded Medicaid and those who live in states that did not. There is no difference in the likelihood of re-employment, likelihood of quitting labor force, and re-employment earnings.

There are two potential limitations in terms of how much my results can be generalized to other subpopulations and contexts. First, my findings that ACA Medicaid expansion affected the unemployment exit rates in the short-run should not be extrapolated to all of the working population. I focus on near-elderly and low-income displaced workers, who may value Medicaid 
very differently than those who are employed and covered by employer-sponsored health insurance plans. This being said, to the extent that my results reject large and persistent effect of ACA Medicaid expansion on unemployment exits (and hence the labor supply among displaced workers), my results are largely consistent with those reported in recent papers. Second, my results also do not imply that short-term labor market disincentives can be eliminated if Medicaid expansion is rolled back, which may happen given the current uncertain atmosphere surrounding health insurance policies at the national level. The endowment effect and loss aversion theories in behavioral economics suggest that people may not respond symmetrically to gaining or losing coverage (Kahneman and Tversky, 1979; Kahneman, Knetsch, and Thaler, 1990), and this might be one of the reasons why previous research found an asymmetric effect of pre-ACA changes in Medicaid on labor supply depending on whether the context was an extension or a cut-back (Garthwaite, Gross, and Notowidigdo, 2014; Gooptu et al., 2016; Dague, DeLeire, and Leininger, 2017).

Given that my results do not indicate that ACA Medicaid expansion had any large and long-term effect on labor supply and re-employment outcomes, I am not able to establish the link between ACA Medicaid expansion and economic well-being of near-elderly displaced workers besides health-insurance coverage. There are a few reasons why my results are not consistent with the predictions from economic theories. As several other researchers have pointed out (Gooptu et al., 2016; Levy, Buchmueller, and Nikpay, 2016), it is possible that displaced workers do not see expanded Medicaid as a long-term solution to health-insurance coverage due to the uncertainty in the political atmosphere. Additionally, as some expansion states find it difficult to meet higher demand for Medicaid services (Miller and Wherry, 2017), displaced workers may also realize that quality of service provided by Medicaid is not comparable to those provided by 
employer-sponsored plans. These factors weaken Medicaid as an alternative to employersponsored coverage, which limits the effect of ACA Medicaid expansion on long-term labor supply, re-employment outcomes, and retirement well-being among near-elderly displaced workers. 


\section{References}

Acemoglu, Daron and Robert Shimer. 2000. "Productivity Gains from Unemployment Insurance." European Economic Review, 44(7), 1195-224.

Addison, John T. and Pedro Portugal. 1989. "Job Displacement, Relative Wage Changes, and Duration of Unemployment." Journal of Labor Economics, 7(3), 281-302.

Card, David, Carlos Dobkin and Nicole Maestas. 2008. "The Impact of Nearly Universal Insurance Coverage on Health Care Utilization: Evidence from Medicare." American Economic Review, 98(5), 2242-58.

Card, David and Phillip Levine. 2000. "Extended Benefits and the Duration of UI Spells: Evidence from the New Jersey Extended Benefit Program." Journal of Public Economics, 78(1-2), 107-38.

Carrington, William J. and Bruce Fallick. 2017. "Why Do Earnings Fall with Job Displacement?" Industrial Relations, 56(4), 688-722.

Centeno, Mário. 2004. "The Match Quality Gains from Unemployment Insurance." Journal of Human Resources, 39(3), 839-63.

Chan, Sewin and Ann Huff Stevens. 1999. "Employment and Retirement Following a LateCareer Job Loss." American Economic Review, 89(2), 211-16.

Chan, Sewin and Ann Huff Stevens. 2001. "Job Loss and Employment Patterns of Older Workers." Journal of Labor Economics, 19(2), 484-521.

Couch, Kenneth A. and Dana W. Placzek. 2010. "Earnings Losses of Displaced Workers Revisited." American Economic Review, 100(1), 572-89. 


\section{Courtemanche, Charles, James Marton, Benjamin Ukert, Aaron Yelowitz and Daniela}

Zapata. 2017. "Early Impacts of the Affordable Act on Health-insurance coverage in Medicaid Expansion and Nonexpansion States." Journal of Policy Analysis and Management, 36(1), 178-20.

Dague, Laura, Thomas DeLeire and Lindsey Leininger. 2017. "The Effect of Public Insurance Coverage for Childless Adults on Labor Supply." American Economic Journal: Economic Policy, 9(2), 124-54.

Department of Labor. "Unemployment Insurance Weekly Claims Data,"

Duggan, Mark, Gopi Shah Goda and Emilie Jackson. 2017. "The Effects of the Affordable Care Act on Health-insurance coverage and Labor Market Outcomes." NBER Working Paper, 23607.

Ehrenberg, Ronald G. and Ronald L. Oaxaca. 1976. "Unemployment Insurance, Duration of Unemployment, and Subsequent Wage Gain." American Economic Review, 66(5), 754-66.

Farber, Henry S. 2017. "Employment, Hours, and Earnings Consequences of Job Loss: US Evidence from the Displaced Workers Survey." Journal of Labor Economics, 35(S1), S235-S72.

Farber, Henry S., Jesse Rothstein and Robert G. Valletta. 2015. "The Effect of Extended Unemployment Insurance Benefits: Evidence from the 2012-2013 Phase-Out." American Economic Review, 105(5), 171-76.

Farber, Henry S. and Robert G. Valletta. 2015. "Do Extended Unemployment Benefits Lengthen Unemployment Spells?" Journal of Human Resources, 50(4), 873-909.

Garthwaite, Craig, Tal Gross and Matthew J. Notowidigdo. 2014. "Public Health Insurance, Labor Supply, and Employment Lock." Quarterly Journal of Economics, 129(2), 653-95. 
Gooptu, Angshuman, Asako S. Moriya, Kosali I. Simon and Benjamin D. Sommers. 2016. "Medicaid Expansion Did Not Result in Significant Employment Changes or Job Reductions in 2014." Health Affairs, 35(1), 111-18.

Gruber, Jonathan. 2000. "Health Insurance and the Labor Market," A. J. Culyer and J. P. Newhouse, Handbook of Health Economics. Elsevier, 645-706.

Gruber, Jonathan and Brigitte C. Madrian. 2004. "Health Insurance, Labor Supply, and Job Mobility: A Critical Review of Literature," C. G. McLaughlin, Health Policy and the Uninsured. Washington D.C.: Urban Institute Press, 97-177.

Hallock, Kevin F. 2009. "Job Loss and the Fraying of the Implicit Employment Contract." Journal of Economic Perspectives, 23(4), 69-93.

Hamersma, Sarah. 2013. "The Effects of Medicaid Earnings Limits on Earnings Growth among Poor Workers." The B.E. Journal of Economic Analysis \& Policy, 13(2), 887-919.

Jacobson, Louis S., Robert J. LaLonde and Daniel G. Sullivan. 1993. "Earnings Losses of Displaced Workers." American Economic Review, 83(4), 685-709.

Kaestner, Robert, Bowen Garrett, Jiajia Chen, Anuj Gangopadhyaya and Caitlyn Feming. 2017. "Effects of ACA Medicaid Expansions on Health-insurance coverage and Labor Supply." Journal of Policy Analysis and Management, 36(3), 608-42.

Kahneman, Daniel, Jack L. Knetsch and Richard H. Thaler. 1990. "Experimental Tests of the Endowment Effect and the Coase Theorem." Journal of Political Economy, 98(6), 1325-48.

Kahneman, Daniel and Amos Tversky. 1979. "Prospect Theory: An Analysis of Decision under Risk." Econometrica, 47(2), 263-92. 
Katz, Lawrence F. and Bruce D. Meyer. 1990. "The Impact of the Potential Duration of Unemployment Benefits on the Duration of Unemployment." Journal of Public Economics, 41(1), 45-72.

Lalive, Rafael. 2008. "How Do Extended Benefits Affect Unemployment Duration? A Regression Discontinuity Approach." Journal of Econometrics, 142(2), 785-806.

Leung, Pauline and Alexandre Mas. Forthcoming. "Employment Effects of the ACA Medicaid Expansions." Industrial Relations.

Levy, Helen, Thomas C. Buchmueller and Sayeh Nikpay. 2016. "Health Reform and Retirement." Journals of Gerontology: Social Sciences.

Madrian, Brigitte C. and Lars John Lefgren. 2000. "An Approach to Longitudinally Matching Current Population Survey (CPS) Respondents." Journal of Economic and Social Measurement, 26(1), 31-62.

Meyer, Bruce D. 1990. "Unemployment Insurance and Unemployment Spells." Econometrica, 58(4), 757-82.

Miller, Sarah and Laura R. Wherry. 2017. "Health and Access to Care during the First 2 Years of the ACA Medicaid Expansions." New England Journal of Medicine, 376(10), 947-56.

Moriya, Asako S., Thomas M. Seldon and Kosali I. Simon. 2016. "Little Change Seen in PartTime Employment as a Result of the Affordable Care Act." Health Affairs, 35(1), 119-23.

Rothstein, Jesse. 2011. "Unemployment Insurance and Job Search in the Great Recession." Brookings Papers on Economic Activity, Fall, 143-96.

Rutledge, Matthew S. 2016. "How Do Financial Resources Affect the Timing of Retirement after a Job Separation?" Industrial and Labor Relations Review, 69(5), 1249-79. 
Schmieder, Johannes F., Till von Wachter and Stefan Bender. 2016. "The Effect of Unemployment Benefits and Nonemployment Durations on Wages." American Economic Review, 106(3), 739-77.

Sommers, Benjamin D., Emily Arntson, Genevieve M. Kenney and Arnold M. Epstein. 2013. "Lessons from Early Medicaid Expansions under Health Reform: Interviews with Medicaid Officials." Medicare \& Medicaid Research Review, 3(4), E1-E19.

Sommers, Benjamin D., Genevieve M. Kenney and Arnold M. Epstein. 2014. "New Evidence on the Affordable Care Act: Coverage Impacts of Early Medicaid Expansions." Health Affairs, 33(1), 78-87. 
Figure I: Expansion versus Nonexpansion States

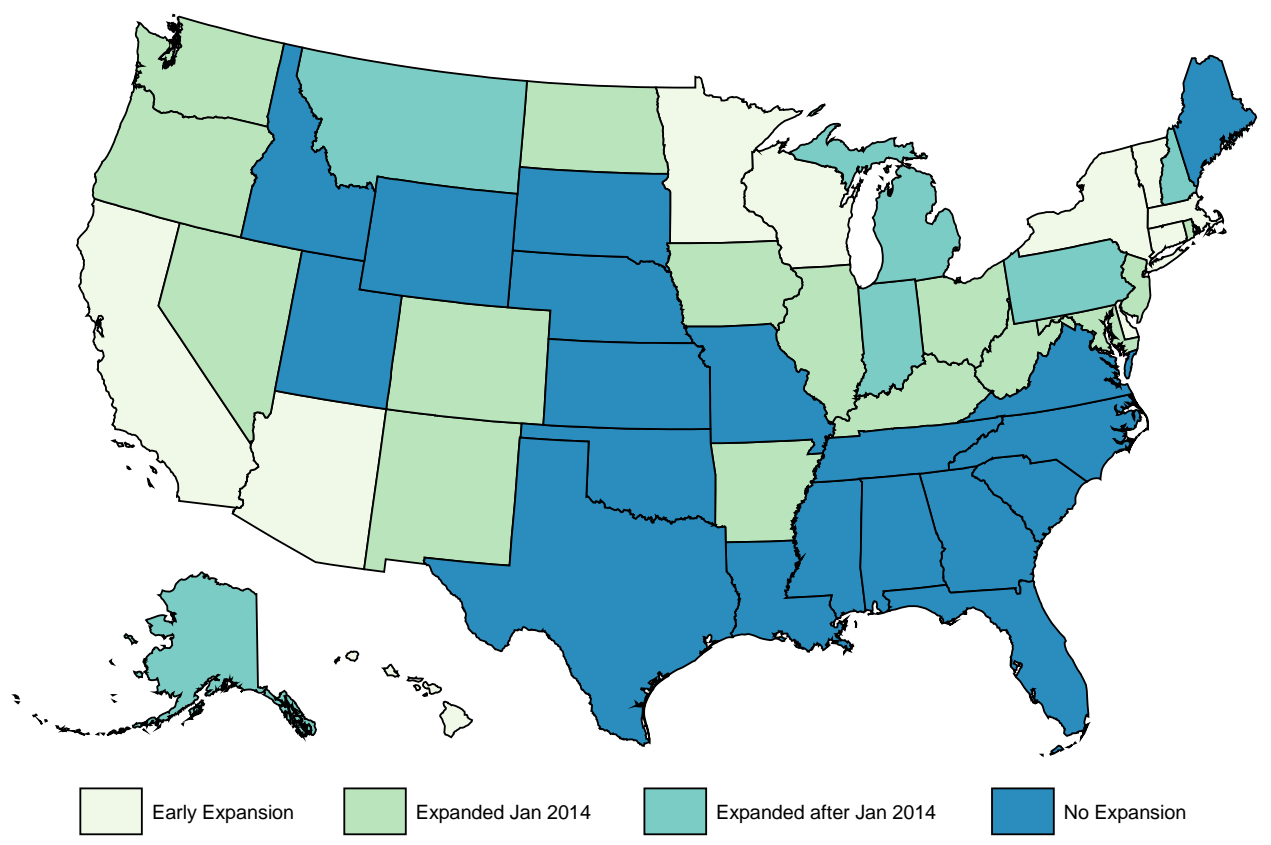


Figure II: Median of Maximum Unemployment Benefits Availability

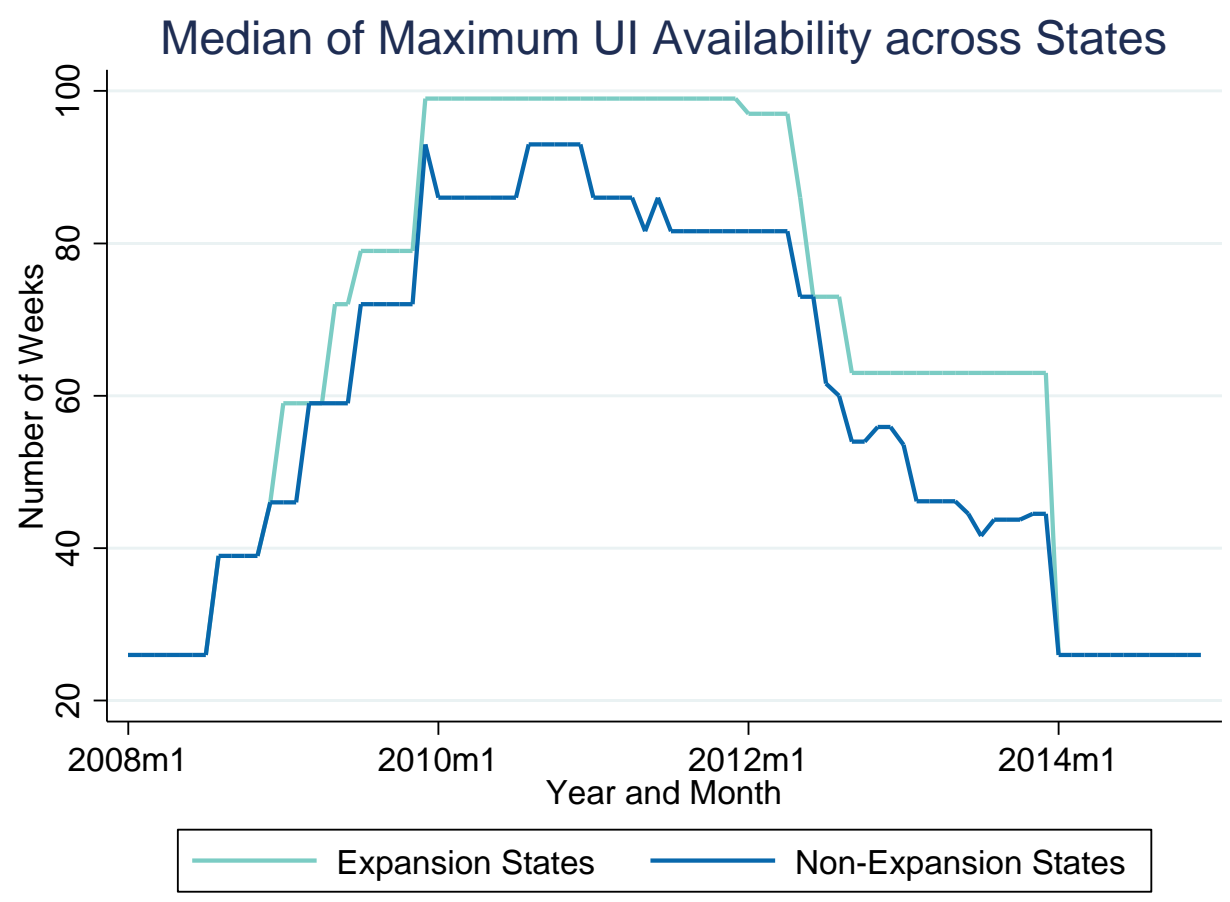


Figure III: “Expansion-Induced Changes” in Unemployment Exits
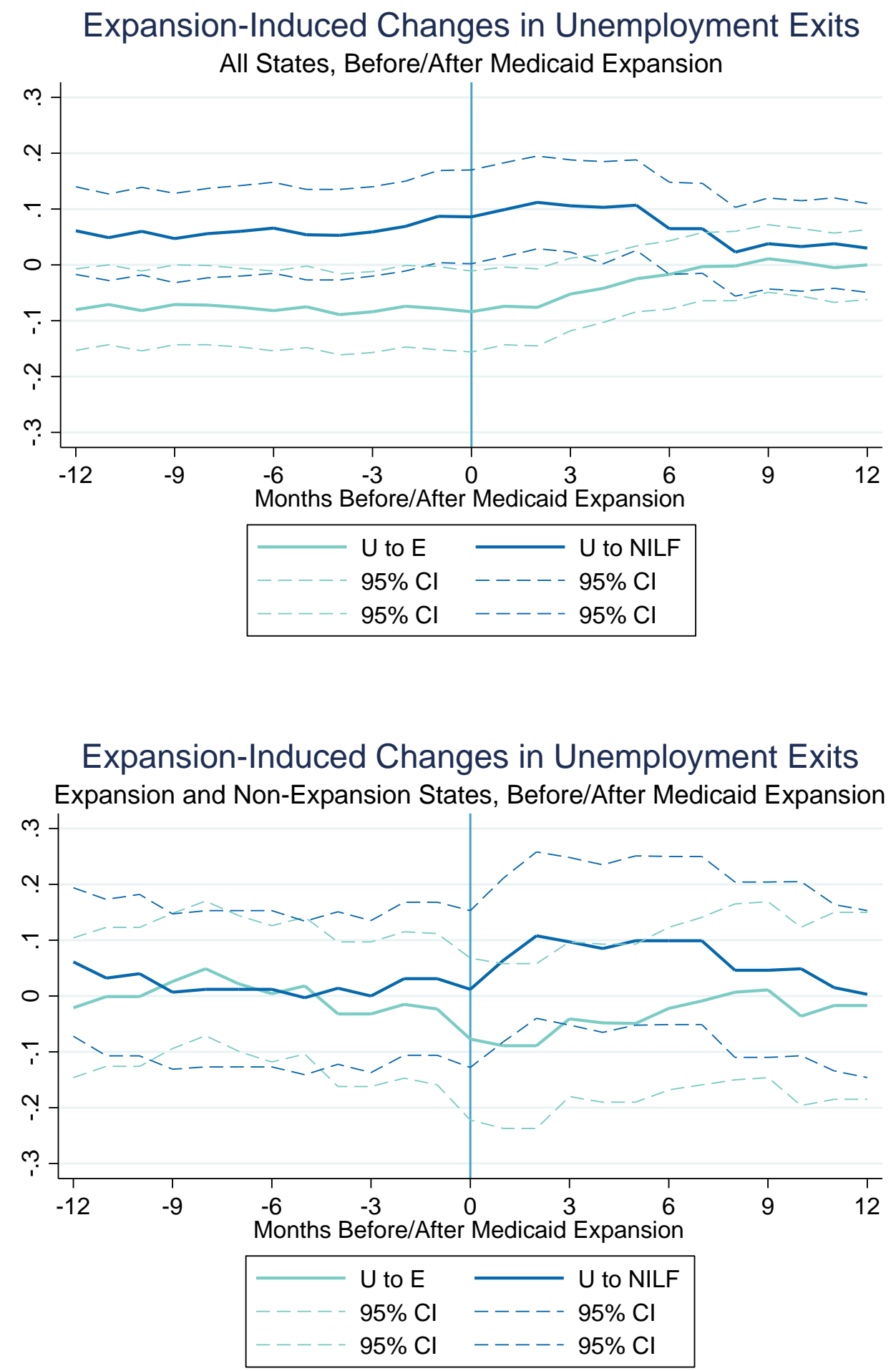
Table I: Descriptive Statistics of Selected Variables in the CPS Sample, 2011-2016

\begin{tabular}{lcccc}
\hline \hline Nearly-Elderly, Low-Income, Nonmarried, Childless, and Nondisabled Displaced Workers \\
\hline & $\begin{array}{c}\text { Early } \\
\text { Expansion }\end{array}$ & $\begin{array}{c}\text { Expanded in } \\
\text { January 2014 }\end{array}$ & $\begin{array}{c}\text { Late } \\
\text { Expansion }\end{array}$ & $\begin{array}{c}\text { Never } \\
\text { Expanded }\end{array}$ \\
\hline Female & 0.454 & 0.478 & 0.430 & 0.467 \\
Age & 55.71 & 55.36 & 55.14 & 55.78 \\
Minority & 0.312 & 0.334 & 0.247 & 0.356 \\
Less than High School & 0.160 & 0.111 & 0.107 & 0.120 \\
High School Graduates & 0.332 & 0.464 & 0.484 & 0.420 \\
Some College & 0.328 & 0.307 & 0.320 & 0.285 \\
College or More & 0.177 & 0.116 & 0.086 & 0.172 \\
Prob. (Unemployment & 0.234 & 0.238 & 0.224 & 0.223 \\
Exit) & & & & \\
Prob. (Exit to & 0.077 & 0.103 & 0.087 & 0.095 \\
Employment) & & & 0.136 & 0.127 \\
Prob. (Exit to NILF) & 0.157 & 0.135 & 93 & 286 \\
\hline Number of Individuals & 230 & 208 & & \\
\hline \hline
\end{tabular}

Note: Weighted with the CPS basic monthly weights. The probabilities of unemployment exits are calculated at the displacement individual-month level, and all other variables are calculated at the individual level. 
Table II: Descriptive Statistics of the DWS Sample

\begin{tabular}{lcccc}
\hline \hline & \multicolumn{3}{c}{ Nonexpansion States } & \multicolumn{2}{c}{ Expansion States } \\
& $\mathbf{2 0 0 8 - 2 0 1 3}$ & $\mathbf{2 0 1 4 - 2 0 1 5}$ & $\mathbf{2 0 0 8 - 2 0 1 3}$ & $\mathbf{2 0 1 4 - 2 0 1 5}$ \\
\hline All Displacement Spells & & & & \\
$\quad$ Number of Spells & 62 & 16 & 51 & 7 \\
Female & 0.508 & 0.400 & 0.392 & 0.642 \\
Age & 55.20 & 54.64 & 55.67 & 55.11 \\
Mean Lost Job Weekly Wage & $\$ 516$ & $\$ 615$ & $\$ 618$ & $\$ 589$ \\
Median Lost Job Weekly Wage & $\$ 447$ & $\$ 421$ & $\$ 451$ & $\$ 607$ \\
Quit Labor Force & 0.108 & 0.071 & 0.147 & 0.367 \\
Re-employment & 0.448 & 0.614 & 0.392 & 0.632 \\
Re-employment Spells Only & & & & \\
$\quad$ Number of Spells & 28 & 9 & 19 & 5 \\
Female & 0.611 & 0.304 & 0.325 & 0.904 \\
Age & 54.92 & 54.61 & 54.66 & 53.74 \\
Search Duration (Weeks) & 10.98 & 18.71 & 14.70 & 12.88 \\
Mean New Job Weekly Wage & $\$ 371$ & $\$ 595$ & $\$ 250$ & $\$ 462$ \\
Median New Job Weekly Wage & $\$ 304$ & $\$ 340$ & $\$ 206$ & $\$ 400$ \\
\hline \hline
\end{tabular}

Note: Weighted with the DWS weights. 
Table III: Effect on Unemployment Exit Rate, Linked Monthly CPS

\begin{tabular}{lccc}
\hline \hline & All Exits & Exit to Employment & Exit to NILF \\
\hline Medicaid Expansion & 0.015 & $-0.084^{* *}$ & $0.086^{* *}$ \\
& $(0.049)$ & $(0.037)$ & $(0.042)$ \\
\hline $\begin{array}{l}\text { No. of Displacement } \\
\text { Individual-Months }\end{array}$ & 1,618 & 1,618 & 1,618 \\
\hline \hline
\end{tabular}

$* *: p<0.05$

Note: Numbers are marginal effects rather than coefficients in logistic models. Standard errors are in parenthesis. Control variables include: gender, race, age, education (four categories), marital status, categories of household income, log of initial unemployment insurance claims in the state, log of total workers receiving unemployment benefits in the state, state non-farm payroll covered under UI, state unemployment rate, and survey year-month and state dummies. Standard errors are clustered by state and time (year-month). 
Table IV: Post-Displacement Outcomes, DWS

\begin{tabular}{lccc}
\hline \hline & \multicolumn{2}{c}{ Panel A: All Spells } & \\
\hline Outcome & Prob.(Quit LF) & Pr.(Re-employed) & Re-employment \\
Specification & Logit & Logit & Proportional Hazard \\
\cline { 2 - 4 } Coefficient & 1.994 & 0.658 & 1.128 \\
No. of Observations & $(2.628)$ & $(1.001)$ & $(1.086)$ \\
\hline & 136 & 136 & 6,785 \\
\hline Outcome & Panel B: Re-employed Only & Re-employment \\
Specification & Search Duration & Log of Weekly Wage & \\
Coefficient & (in Weeks) & in New Job & Proportional Hazard \\
\cline { 2 - 4 } No. of Observations & Tobit & Linear & 0.587 \\
\hline \hline
\end{tabular}

$* *: p<0.05$

Smaller sample size in the second column of Panel B relative to the first column is due to missing new job wage data among some re-employed DWS respondents.

Note: Standard errors are in parenthesis. Control variables include: gender, race, age, education (four categories), marital status, tenure in lost job, weekly wage in lost job, when job was lost (one or two years prior to survey), and survey year and census region dummies. Standard errors are clustered by census region and year. 
Table V: Post-Displacement Outcomes, DWS; Relaxed Sample Restriction

\begin{tabular}{lccc}
\hline \hline & \multicolumn{3}{c}{ Panel A: All Spells } \\
\hline Outcome & Prob.(Quit LF) & Pr.(Re-employed) & Re-employment \\
Specification & Logit & Logit & Proportional Hazard \\
\cline { 2 - 4 } Coefficient & 0.205 & 1.147 & 1.783 \\
& $(0.537)$ & $(0.807)$ & $(1.150)$ \\
No. of Observations & 295 & 295 & 13,072 \\
\hline & \multicolumn{4}{c}{ Panel B: Re-employed Only } \\
\hline Outcome & Search Duration & Log of Weekly Wage & Re-employment \\
& (in Weeks) & in New Job & \\
Specification & Tobit & Linear & Proportional Hazard \\
\cline { 2 - 4 } Coefficient & -21.33 & 0.754 & 2.208 \\
& $(12.34)$ & $(0.660)$ & $(1.327)$ \\
No. of Observations & 140 & 124 & 2,272 \\
\hline \hline
\end{tabular}

**: $p<0.05$

Smaller sample size in the second column of Panel B relative to the first column is due to missing new job wage data among some re-employed DWS respondents.

Note: Standard errors are in parenthesis. Control variables include: gender, race, age, education (four categories), marital status, tenure in lost job, weekly wage in lost job, when job was lost (one or two years prior to survey), and survey year and census region dummies. Standard errors are clustered by census region and year. 